\title{
Academician Glushkov and Grandmaster Fisher
}

\author{
Karachenets Dmitryi \\ St. Derevlyanskaya, 19a, of. 54, Kyiv 04119, Ukraine
}

\begin{abstract}
In the first part of the article, the incomprehensible victories of the American grandmaster Robert Fisher over the candidates Mark Taimanov, Bent Larsen and Tigran Petrosyan in 1971 for the right to play the match for the World Chess Champion title with the former champion Boris Spassky and the victory over the champion himself in 1972 are first served as a detective story hypothesis proposed by Academician Viktor Glushkov. According to this hypothesis, R. Fisher used the prompts of a super-productive computer installed in the United States, in which a highly efficient computer chess program was played along with the matches. Communication with the computer provided a team of employees of the CIA. In the second part, the author, having reviewed briefly the history of computer chess programs, rejects the hypothesis of the academician and proposes his own.
\end{abstract}

Key words: Chess game, chess match, chess competition, international chess tournament, chess championship, chess player, computer chess program, international master, grandmaster, candidate (contender, applicant, challenger), world chess champion, debut, defense, endgame, victory, draw, defeat.

\section{Introduction}

As "computer program" intertwined with the game of invincible Robert ("Bobby") Fischer on his way to "crown" of undefeated world chess champion in the story, told Glushkov Viktor Mikhailovich his "bewitched" the audience in the room "suite" of "Verkhovyna" hotel in Lviv dark night of August 8, 1979 ? Can the author of this story convey to the Reader the whole intrigue of the exciting detective story? His story about the four stages of Robert Fisher "impetuous rise" to the "chess Olympus" Viktor Glushkov began by saying that in his opinion, and the opinion of many famous psychologists - chess lovers and experts, with whom he had a conversation on this topic, in games against contenders for the title of world champion Mark Taimanov, Bent Larsen, Tigran Petrosian in 1971 and against the former world chess champion Boris Spassky in 1972 played a "person" with the level of intelligence on a few "steps" higher than that Robert

Corresponding author: Karachenets Dmitryi, Ph.D., research fields: mathematical, algorithmic, applied software and information support of automated control systems for technological processes, complexes, systems in the chemical industry and oil pipeline transport.
Fisher, albeit very gifted, talented, extraordinary, and as a very successful chess player, whom the chess world knew before 1971. Come on, Reader, together remember how those "take-offs" of R. Fisher went through.

\section{Materials and Methods}

\subsection{Robert Ficher Matches Against Contenders}

\subsubsection{The Quarterfinal Match}

The Quarterfinal match of contenders Mark Taimanov-Robert Fischer took place in Vancouver, Canada. Match result is 6:0 in favor of Fisher. (Information.

Mark Evgenievich Taimanov was born on February 2, 1926 in Kharkov, where his parents studied. Father - at the Polytechnic Institute, mother-at the conservatory. It is not surprising that after his parents moved to Leningrad, the current city of St. Petersburg, young Mark became a chess player and pianist. Having received his primary musical education from his mother, he later studied piano at the Leningrad Conservatory, where his future wife, Lyubov Brooke, was also studying with him.

Chess section of the Leningrad Palace of Pioneers 
he began to attend with 10 years. Having taken only after the Great Patriotic War (as part of the World War II) 14 times participation in chess championships of Leningrad, 5 times he became the champion. In the USSR championships he played 23 times, but only once, in 1956, became the champion. He received the title of international grandmaster in 1952, and already in 1953 he played for the first time in the tournament of contenders, then a circle, taking a place in the middle of the table.

Being busy in many chess competitions, including in major international tournaments, he did not leave his concerts regularly performing in a duo with his wife.

Mark Taimanov linked his chess creativity with the theory of the main systems in the debut of the Sicilian Defense and the defense of Nimzovich. As a chess journalist, he lad a section in the famous Soviet journal Ogonyok.

Dividing 1970 5th-6th places in the inter-zonal tournament, held in Palma de Mallorca, he gained the right to play in the quarterfinals of the contenders tournament, where his opponent was Robert Fisher, the meetings to which he had previously suffered one defeat and one meeting brought a draw.

A great defeat of Taimanov with a "dry" score came as a shock to the Soviet Chess Federation, and he was subjected to a series of repressions:

- he was deprived of the title of Honored Master of Sports of the USSR (he was restored to the rank only in 1991);

- he was reduced by the government scholarship;

- he was no longer sent abroad to tournaments.

Such an attitude towards an international grandmaster was also caused by the fact that after Mark Taimanov returned from a match he had lost at a customs office in the USSR, during a search, he was found to have a banned book of banned writer Alexander Solzhenitsyn.

Mark Taimanov was the only one of R. Fisher's three rivals in the Contenders Tournament who was alive in May 2014. In the weekly "Top Secret" the author of the story was able to get acquainted with his memories of that match.

In May 2014, the chess school of the grandmaster Mark Taimanov was opened in St. Petersburg.

Taimanov died on 28 November 2016 in St. Petersburg, at the age of 90 .

\subsubsection{Semifinal Match}

Returning to the "takeoffs" of Robert Fisher, we note that the Semifinal match of the applicants, but now with the Danish Bent Larsen, Fisher won again with the same "dry" score 6:0 in Denver, USA.

(Information.

Jörgen Bent Larsen was born on 03.04.1935 in Tisted, Denmark. He learned to play chess at the age of 7. At the age of 12 , he began studying chess literature on his own. The successful student was also a successful chess player and at the age of 19 became the champion of Denmark. For the best result at the World Chess Olympiad in Moscow in 1956, where he performed on the first board for the Danish national team, he was awarded the title of Grand Master.

Bent Larsen never had a coach; there was only an assistant-his wife. But in 1959 he himself became the second of Robert Fisher at the Contenders Tournament in Yugoslavia.

If at the interzonal tournament in 1958 he suffered a failure, then in 1964 in the same tournament in Amsterdam, he, sharing 1-4 places with other participants of the tournament, became for the first time a contender for the world championship. Reaching the semi-finals, in a bitter struggle (4.5:5.5), he lost to the Soviet grandmaster Mikhail Tal. But, as a true Scandinavian - a native of Jutland, the northern part of Denmark, he was never afraid of defeat. And two years later, in one of the tournaments, he twice defeated Tigran Petrosyan, who was the world champion at that time. In 1967 he became the first winner of the Oscar chess prize.

Bent Larsen, being a chess journalist, was highly educated and mastered many European languages, including Russian. 
He had something in common with Robert Fisher: knowledge of languages, knowledge of Soviet chess literature, the desire for a dynamic game of chess, combined with the desire for solitude. But, on the other hand, they were completely different people. In contrast to the egoism and egocentrism of Fisher, Bent Larsen was distinguished by calmness, sociability and friendly attitude towards the people around him.

With Robert Fisher, they were irreconcilable rivals. Interestingly, at the international tournament in Santa Monica in 1966 and at the interzonal tournament in Palma de Mallorca in 1970, the one in which Mark Taimanov reached the quarter-finals of the contenders tournament, and Larsen himself went to the semi-finals, Bent Larsen had victories over R. Fisher. And although the total score for all previous tournaments was 4.5:2.5 in favor of Fisher, no one could expect a "dry" score in 6 games in favor of Fisher in the semifinal match of the 1971 contenders.

Bent Larsen adhered to a highly combinational game, from childhood he was fascinated by the King's gambit. Later he developed a debut, which was named the debut of Nimzovich-Larsen and brought him many victories in games with the strongest chess players of the world. As man of principle, he avoided a draw, was optimistic, and sometimes overly self-confident. Perhaps it affected his cruel defeat from the "chess rational machine", which in his games was Robert Fisher.

As "chess rational machines" there also were creating "computer chess programs". And here, Bent Larsen was the first international grandmaster who lost to the computer program of Deep Thought. However, none of the seven world chess champions from Mikhail Botvinnik to Anatoly Karpov had a "dry" score in the games against him.

Bent Larsen died on 09.09.2010 at Buenos Aires, which will be connected with our story about the next "takeoff" by Robert Fisher in 1971).

\subsubsection{Final Match}

In the final match of the contenders, played by
Robert Fischer against Tigran Petrosian in Buenos Aires, Argentina, the score was 6.5:2.5 in favor of Fisher.

(Information.

According to Wikipedia - the free encyclopedia—with some reductions "Tigran Vartanovich Petrosian (Arm., June 17, 1929, Tbilisi, August 13, 1984, Moscow), Soviet chess player, the 9th world chess champion from 1963 to 1969, International Grandmaster (1952), Honored Master of Sports of the USSR (1960), PhD, four-time champion of the USSR (1959, 1961, 1969, 1975), three-time champion of Moscow (1951, 1956 (with V. Simagin), 1968 (with D. Bronstein), chess theoretician journalist and editor of the monthly Chess Moscow (1963-1966), the founder and chief editor of the weekly 64 (1968-1977), nine-winner of the Chess Olympiads in the team of the USSR. He was nicknamed "Iron Tigran" for his art of defense. He played ten times in a row in contender competitions (including as the current world champion). Some sources call him the "most hard-won player in the history of chess".

Tigran Petrosyan holds many records. Thus, he held six USSR championships without a single defeat; at ten World Chess Olympiads for 20 years (since 1958), he scored 79 victories, 50 games brought in a draw and suffered only 1 (!) defeat. In 1964, Petrosyan, together with Fisher with a rating of 2,690, headed the first unofficial international list of chess players rated by Elo (Arpad Elo).

"I believe the only logical, right game" it was his credo. The same Robert Fisher wrote about him: "Petrosyan was well able to see and eliminate the danger 20 moves before it arises!"

Tigran Petrosian has made a significant contribution to the theory of debuts such as the King's Indian defense (system Petrosyan), Queen's Indian (version Petrosyan), the French defense, the Karo-Kann defense and a number of others.

Tigran Petrosian became world champion in 1963, beating the "most famous" Mikhail Botvinnik. And in 
1966, he confirmed this title by winning the world championship match with the challenger Boris Spassky. Having devoted, apparently, quite a lot of time to the defense of his Ph.D. in philosophy in 1968 on the topic "Some Problems of the Logic of Chess Thinking" in 1969 he gave up the title of champion to the same Spassky. In the next tournament of the candidates' matches, fate brought him together in the final match with Robert Fisher.

Before this match, Petrosyan's personal account with Fisher was a draw-3:3:12, that is, each of them had three wins and three losses in personal meetings with 12 games played in a draw. And suddenly: 5 defeats in all with one (1) victory and three (3) draws! This is the same score 6.5:2.5 final match applicants in 1971, held in Buenos Aires.

Why is that?

\subsection{Robert Ficher Match against World Chess Champion}

The fourth stage of the "rapid take-off" of Robert Fisher to the "chess Olympus" is his match for the world championship with Boris Spassky, held in Reykjavik, Iceland's capital, in 1972.

(Information.

Again we turn to Wikipedia: "Boris Vasilievich Spassky (born January 30, 1937, Leningrad, USSR), Soviet and French chess player, 10th World Chess Champion (1969-1972), International Grandmaster (1955), Honored Master of Sports of the USSR (1965), Two-time champion of the USSR (1961, 1973), a ten-time participant in Chess Olympiads.

Spassky declared himself in 1955 by winning the world championship among juniors and selecting in the Contenders Tournament. But then he could not be selected in the two Contenders cycle in a row. In 1966, he won the right to a world championship match against Tigran Petrosian, but was defeated. Three years later, in a match between the same rivals, Spassky won the crown. In 1972, he lost the match to Robert Fischer. In 1976, the grandmaster had emigrated to France, in 2012 he returned to Russia. He continued to perform at the highest level until the end of the 1980s. Now Boris Spassky is the oldest among the living world chess champions.

At first, Spassky was distinguished by the attacking combinational style of play. Over time, he improved his debut repertoire, positional skills and endgame technique and during the heyday was a versatile player, exceptionally strong in all components.

The childhood of Boris Spassky was dramatic. In the summer of 1941, shortly before the beginning of the blockade of Leningrad at the age of 4 years, along with his elder brother for 3 years, he was evacuated in the Kirov region, to an orphanage, on the way in the train, miraculously avoiding death from German bombs. Only two years later, their parents escaped from besieged Leningrad and the whole family settled in the suburbs of Moscow. But a year later, his father, who was the commander of some automotive unit, left the family, leaving his wife in the third month of pregnancy. Sister Iranda, born in November 1944, subsequently became the grand master of draughts and the vice-champion of the world in 100-checkers. She, apparently, was helped by her middle brother Boris, who already at the age of 5 learned to play chess in the orphanage and, of course, draughts checkers.

In the summer of 1946, after the family returned to Leningrad, I remind you that the current St. Petersburg city, 10-year-old Boris "disappeared" from morning to late evening in the summer chess pavilion in the central park of the city. And after the pavilion was closed for the winter, he entered the chess section of the Leningrad Palace of Pioneers. His first coach was Vladimir Zak, under whose leadership he fulfilled the standard of the I-st category a year later, becoming the youngest first-rank player in the country.

In 1952, his new coach became an international master, and later the grandmaster, Alexander Tolush, a follower of the combinational game. And already in that year, Boris Spassky in the championship of Leningrad took 2nd place after Mark Taimanov. In 
1953, in Bucharest, he fulfilled the norm of an international master, and in 1955, appearing for the first time in the USSR Championship, he shared 3-6 places with Mikhail Botvinnik, Tigran Petrosyan and George Ilyvitsky. Following this, Boris Spassky, appearing in Antwerp, became the first Soviet world chess champion among youths.

A week after the completion of the youth championship, he took part in the interzonal tournament from August 15 in Gothenburg. Here he not only fulfilled the standard of the grandmaster, becoming at that time the youngest grandmaster in the history of chess, but also won the right to participate in the tournament of candidates for the chess "crown".

In the tournament of applicants in 1956 he divided 3-7 places. Not quite exactly he performed in two USSR championships. But in 1959 he graduated from the Philological Faculty of the Leningrad University, receiving a degree in journalist.

In the spring of 1960, Boris Spassky again showed himself. It was at the tournament in Mar del Plata, where he, having played for the first time against Robert Fisher, defeated him. And together at that tournament they shared 1-2 places. But in the USSR championship in the same year, Spassky played poorly (9-10 place). At the next, the 28th USSR Championship at the beginning of 1961, he again did not get into the top four for participating in the games of world championship applicants.

But with a new coach Igor Bondarevsky he significantly improved the quality of the game and made a number of achievements over the next ten years:

- at the end of 1961 for the first time he became the champion of the USSR;

- having played in July 1962 on the 1st board for the USSR national team, who won 1st place in the world team championship among students, he passed the tournament without defeat and scored 7.5 points out of 9 ;

- in 1962, for the first time, he played for the USSR national team at the Chess Olympiad in Varna, having won the individual first place on the third board without a single defeat (Botvinnik-1st, Petrosyan-2nd board);

- having moved to Moscow in 1963, at the end of 1963 he divided 1-3 places with Kholmov and Stein at the USSR Championship. But in the extra match-tournament of "three", Leonid Stein won;

- he won the qualifying round for the world championship match in 1966, passing: (1) the USSR championship mentioned above in 1963; (2) the zonal FIDE tournament in the first months of 1964, in which seven Soviet grandmasters played a round tournament in two stages and three winners (B. Spassky, who won with 7 points out of 12, and D. Bronstein and L. Stein) were held in interzonal tournament where V. Smyslov and M. Tal joined them from the USSR; (3) the inter-zonal tournament in Amsterdam in May-June 1964, dividing 1-4 places with B. Larsen, V. Smyslov and M. Tal; (4) a quarter-final match (1965) of ten games with P. Keres - the second prize winner of the previous candidates tournament, winning the match with a score of $6: 4$; (5) a semi-final match with $E$. Geller, having finished it ahead of time with a score of 5.5:2.5 (E. Geller, who had a hard way to reach the semi-final, also beat V. Smyslov ahead of schedule in the quarterfinal); (6) the final match with M. Tal, defeating him ahead of time with a score of 7:4 (M. Tal on the way to the final won ahead of time in the quarterfinal of Lajos Portisch and barely won the semi-final against B. Larsen);

- as a challenger, he lost the world championship match in Moscow in the first half of 1966 to $\mathrm{T}$. Petrosyan, who won an early victory with a score of 12:10 (although in the last two games, the results of which were no longer valid, B. Spassky scored 1.5 points, so the final score was 12.5:11.5 in favor of $\mathrm{T}$. Petrosyan);

- in the summer of 1966, he won without defeat in Santa Monica (USA) the Pyatigorsky Cup tournament, where 10 grandmasters, including world champion $\mathrm{T}$. Petrosyan, R. Fisher, B. Larsen and S. Reshevsky, 
played in two rounds, and won in micro-matches over his competitors R. Fisher and B. Larsen;

- at the end of 1966, he played 10 games on the 2nd board at the Havana Chess Olympiad, winning two and reducing the rest to a draw (including $\mathrm{R}$. Fisher, when he replaced T. Petrosyan on the 1st board in a match with their main competitors, the Americans);

- he won the challenger's cycle in 1968, where he defeated Yefim Geller in the quarterfinal with a score of 5.5:2.5, in the semi-finals with the same score of B. Larsen (in Malmo in June 1968) and in the final-Viktor Korchnoi with a score of 5, 5:3.5 (Kyiv, autumn 1968);

- with the new coaching staff as part of the old coach I. Bondarevsky and the new Nikolai Krogius, he carefully prepared from autumn 1968 to April 1969 for a world championship match in a hotel in the Moscow suburban town of Dubna;

- in the world championship match, which began in Moscow on April 14, 1969, he won an early victory with a score of 12.5:10.5 over former world champion T. Petrosyan;

- the first tournament in the title of world champion he held in San Juan (Puerto Rico) in October 1969, where, having won 8 games and 7, drawing in a draw, he took 1st place;

- but at the end of 1969, in a stronger tournament due to accumulated fatigue, he took only 5th place with 10 points out of 17 , and 1st place was taken by $B$. Larsen with 12th points;

- in the spring of 1970, in the "Match of the Century" between the USSR national team and the rest of the world team, on the 1st board, he played three games with a score of 1.5:1.5 against B. Larsen, who was replaced instead of R. Fisher;

- in the fall of 1970, at the XIX Olympiad in Siegen (Germany), he won the individual competition on the 1st board, and the USSR national team won "gold" (his victory over R. Fisher in the central match of the USSR - the United States of this Olympiad was named by future world champion Garry Kasparov the crown of the champion period of B. Spassky).

In 1971, when the entire chess world was "bewitched, enchanted and shocked" by the brilliant victories of Robert Fisher over his rivals - contenders for the world champion title with champion Boris Spassky, the champion himself, it seems, "sat with folded arms". Of course, there was participation in 4 tournaments, but this did not give him good match practice with strong opponents. For example, the international tournament in Gothenburg, he passed without defeat, scoring 5 wins and making a draw in 6 games, but took only 3rd place. And in Moscow, at the Alekhin Memorial, he, in general, shared 6-7 places, winning 4, making a draw with 11 games and suffering 2 (!) defeats. And only at the open championship of Canada in Vancouver, in the city where Robert Fisher "defeated" Mark Taimanov, he took the 1st place, gaining 9 points from 11 possible. That is, if the champion did not "sit", but "traveled," then not especially "straining his hands" and "head", probably, too.

Only in the fall of 1971, when R. Fisher decided for a future match for the World Championship, as a rival for B. Spassky, preparations for this match began. What, before that, was the hope of T. Petrosyan's victory in the final match of the applicants? And then for the match with him they would have had time to prepare? Of course, because only less than three years ago, after a thorough preparation, B. Spassky won the match in 1969 against former champion T. Petrosyan. And R. Fisher? But what about R. Fisher, if Boris Spassky had 2 victories over Robert Fisher without any defeat and 2 games played a draw? Really, Russian conceit? But already the victory of "dry" of R. Fisher over B. Larsen should have been given to the coaching staff and the champion B. Spassky himself to be forced to do serious preparation for the match with R. Fisher? (Lord, how does this remind of the position of the Soviet leadership before the Second World War and the beginning of the Great Patriotic 
War?).

To the late preparation for the decisive match it was added and "leapfrog" with the coaches (Well, it is like with the highest command in the Red Army before the War).

With the start of preparation for the match there were also difficult negotiations on the venue. In the coaching staff, consisting of Igor Bondarevsky, who had worked with Boris Spassky for many years, and connecting to him Nikolai Krogius in the fall of 1968 during the preparation for the world championship match in 1969 with former champion Tigran Petrosian, now Efim Heller also entered. Note that E. Geller, like B. Spassky, had a "preponderance" in meetings with R. Fisher: 5 victories with 3 defeats and 2 draws. The disagreements that arose at the headquarters led to the breakdown of B. Spassky's relations with his long-time coach I. Bondarevsky, whom E. Geller could not replace. The "doubled" confidence now "in one's own strength" was followed by an unplanned training process. And this was already a direct path to defeat in the future match.

Boris Spassky, unlike Robert Fisher, was not a "rational chess machine". B. Spassky was talented, but he lacked rationalism. His first teachers V. Zak and A. Tolush fascinated him with a combination, maneuverable game, but did not sum up a solid "debut foundation" for it. Although I. Bondarevsky, and then N. Krogius, something were corrected in the debut preparation of the future champion, but they could not achieve strength in the "debut foundation" of B. Spassky. Yes, and the champion himself paid little attention to debuts. Hence, in the chess heritage of B. Spassky, no well-developed "debut system" or, at least, "variant", named after him, remained. The same could be said about the endgame developments. And this, apparently, led to "disruptions" in tournaments and to frequent "fatigue", since his poorly rational game system took away from him a lot of strength.

The quality of his play depended to a large extent on his physical health and emotional state. This, apparently, was taken into account by Robert Fisher, turning the world championship match into a "performance".

According to the agreement, signed on 03.20.1972, the first half of the match was to begin on June 22, 1972 in Belgrade (Yugoslavia), and the second half - to continue in Reykjavik (Iceland).

However, ("1st act of the performance") R. Fisher immediately made a demarche because of disagreement with the financial conditions for the match. After the new negotiations, Yugoslavia withdrew its application ("Hypothesis 1": According to Glushkov, but in interpretation of the author of this narration: was not remote from the sea "Belgrade" the main "target" of Fisher in this "1st act"?).

Now FIDE President Max Euwe defined the location of the match in the city of Reykjavik, and postponed the start of the match to July 2 ("Hypothesis 2": Do not become a "smokescreen" for the plans R. Fisher and his "Staff" the "bay", that "Smoke Bay"-Reykjavík, which gave its name to the city of Reykyavik?).

And again the "performance" ("2nd act"): the challenger R. Fisher, for no perspicuous reason, for the organizers of the match, of course, did not appear by the announced start date of the match ("Hypothesis 3": Was not by July 2, 1972 the team of R. Fisher delivered the yacht with the equipment to the "bay", which was supposed to provide communication of the challenger during his matches with the "computer chess program" played in parallel with the match on the high-performance computer installed in the USA). A scandal and protest from the Soviet side followed. Many saw in the behavior of the applicant R. Fisher the desire to exert psychological pressure on the champion B. Spassky. And it is hard to disagree with them.

M. Euwe decided to postpone the start of the match, with which Boris Spassky - a gentleman by nature - agreed with him. In the end, the match began on July 11th. 
In the first game the challenger made a crude error in the endgame and lost this game. Robert Fisher did not appear for the second game, because the organizers of the match refused to meet his requirements for the hall for the games. The applicant was considered a defeat and the score was 2:0 in favor of B. Spassky.

("Hypothesis-4": First explanation: according to interpretation of the "take-off" of R. Fisher's "intellect" during the four described stages of his "ascension" to the chess Olympus, which was presented by academician Viktor Mikhailovich Glushkov to his "fascinated" listeners in the suite of Hotel "Verkhovyna" in Lviv on a dark night of 08.08.1979, the challenger during his games used a special metal, basically, chair that served as an antenna on meter waves for data exchange of $R$. Fisher with a "computer chess program". If there was a little hall for games and the television cameras of television reporters were close to the table of the playing rivals, then strong radio interference could be created. The hall also was not supposed to "shield" the radio waves of the meter range, on which there was an exchange of messages between the miniature transceiver at $\mathrm{R}$. Fisher and the radio equipment installed on the yacht. Hence the "hypothesis 4": the room in which the first match took place, or did not comply with these requirements, or the equipment of radio and television journalists in the room was not at a "respectful distance" from the applicant. The Reader, based on the main idea of Academician V. Glushkov, may try to give his own interpretation of the result of the first and failed second game between the rivals in this match.

The Reader can now transfer this idea to the previous matches of R. Fisher with former contenders for the chess "crown" in the cycle M. Taymanov, B. Larsen and T. Petrosyan. According to academician Glushkov, in the bays of Vancouver (the match with M. Taimanov) and Buenos Aires (the match with T. Petrosyan) there were also yachts with the "team" of R. Fisher. As for the "land" Denver (the match with B.
Larsen), then with it, located in the United States, the "team" of R. Fisher should have had no problems. Another thing was the "land" city of Belgrade, the former capital of the former Yugoslavia (see "hypothesis-1").

The description of the subsequent games played by B. Spassky and R. Fisher in the match will be taken from Wikipedia, omitting details that are not essential for us:

"In the third game, Fisher applied the debut novelty with black, the world champion did not react in the best way and eventually lost. In the fifth game, Fisher - again with Black - equalized the score, and in the sixth game, he stepped forward, making a direct attack. Then he won the eighth and tenth meetings. The eleventh game was won by Spassky, this game is notable for the fact that Fisher's only defeat was black in the 'poison pawn' variation in the Sicilian defense. In the thirteenth game, Fisher scored a spectacular victory in the endgame, in which an avalanche of black pawns of the challenger confronted the white rook. When playing, both opponents played very strongly, and the game should have ended in a draw, but Spassky made a decisive mistake with the 69th move. Fisher's advantage after this victory reached three points, and he brought the match to victory. In the twenty-first game, Spassky made a mistake in the endgame and the next day, September 1, did not come to finish the game, having passed the game on the phone and, as a result, the match, which ended in victory for challenger $12 \frac{1}{2}: 81 / 2$ ".

If my memory serves me right, then in the eleventh game "computer chess program", in the opinion of V. Glushkov, who with his staff from the Institute of Cybernetics of the Academy of Sciences of the Ukrainian Soviet Socialist Republic in the research into artificial intelligence worked on the creation of a perfect "computer chess program", could, because of the "poisoned" pawn, make a mistake that R. Fisher with his skill level would not have allowed if he had not trusted the "program". But maybe a similar 
situation has developed in the only game won by $\mathrm{T}$. Petrosyan? I do not remember exactly.

No matter how it was there, but the last match really showed insufficient pre-match preparation of B. Spassky in debuts and endgames, to which the author tried to draw the attention of the Reader above.

And again from Wikipedia:

"At a meeting at the USSR Sports Committee after the match, among the reasons for the defeat, omissions were noted in preparation for the match and the lack of playing practice at the highest level of Spassky. Kasparov also wrote about this, noting as an important factor the change of coach. Spassky himself later said that at that time Fisher was really the strongest in the world."

\subsection{Robert Fisher}

So who was Robert Fisher?

(Information.

According to Wikipedia (with details omitted):

"Robert James 'Bobby' Fisher (March 9, 1943, Chicago, USA, January 17, 2008, Reykjavik, Iceland), American chess player, eleventh world champion (1972-1975). According to the magazine Šahovski Informator he was the strongest chess player of the $\mathrm{XX}$ century.

His mother, Regina Fischer, née Vender, a Swiss Jewish woman whose family moved to Switzerland from Poland and Russia; the father was considered as Hans-Gerhard Fischer, a German Jew, a biologist, a communist who emigrated from the USSR, where he met Regina, who studied in First Moscow State Medical University named after I. M. Sechenov.

In 1939, the married couple left the USSR and moved to America, but from that moment they lived separately; Regina settled in the United States, and Gerhard in Chile, and he, as a Communist, was not allowed to enter the United States. After the end of World War II, Gerhard returned to Germany. It is believed that the real father of Robert was Paul
Nemeni, a Hungarian Jew who fled from Nazi Germany to the United States, a mathematician, a member of the Manhattan project. Nemeni took an active part in raising the boy, cared for him, paid for his studies until his death in 1952, twice he unsuccessfully tried to sue Regina's right to educate Robert, saying that 'his mother has a mental disorder and she cannot give her son adequate education.

After the war ended, the mother and children moved to Brooklyn. When Robert was six years old, sister Joan had taught him to play chess. He immediately manifested a natural gift to chess, which the boy was actively developing. Passion for chess completely turned Robert away from communication with peers (he perceived only those who could play chess with him ...)"

Having joined the local chess club, at the age of 10 he took part in his first chess tournament and won it. At age 13, Robert Fisher became the champion of the United States among juniors, and at age 14-and the "adult" champion of the United States, but the youngest in history. Wunderkind! Possessing a magnificent (!) memory, he was able to study several languages (Spanish, German, Russian, Serbo-Croatian), as was mentioned above in the description of Bent Larsen's "chess biography". At the age of 15, Robert left school to devote himself only to chess. His goal was to win the title of world champion. For this, he not only worked hard on chess, but also led a sports lifestyle, maintaining health, physical and mental, skating, skiing, swimming, tennis.

Having won the US Championship, Robert Fisher won the right to participate in the next interzonal tournament, which took place in Yugoslavia (in Portorož) in 1958. Here he divided 5-6 places, not only exceeding the norm of the international grandmaster, but also getting the right to participate in the tournament of applicants. At 15 and a half years old, young Robert became the youngest grandmaster in chess history, beating the previous record of Boris Spassky. 
The debut repertoire, which was still limited, along with a reassessment of his own chances in the candidates' tournament next year, in 1959, allowed Fisher to divide again, but only 5-6 places, just like a year ago in an interzonal tournament. At the same time, to the winner of the Contenders Tournament, Mikhail Tal, he lost his "micromatch" "dry"-0:4.

The not very prestigious result achieved by the pretentious American prodigy at the Candidates Tournament, made him take more self-training.

The not very prestigious result achieved by the pretentious American prodigy at the Candidates Tournament, made him take more self-training.

If he was "out of reach" in the USA, becoming invariably a winner in the US championship for several years in a row, then in international tournaments his successes were at first modest. So, in 1959, he did not rise above the 3-4th place, and in the candidates' tournament, Bled-Zagreb-Belgrade (Yugoslavia, at that time), again divided only 5-6 places. Starting in 1960 with a successful performance at a tournament in Mar del Plata (13 wins, 1 loss and 1 draw), dividing the 1-2nd place, at the next tournament in Buenos Aires, he "fell off a cliff", taking only 13-16 places (with only 3 wins, 5 losses and 11 draws).

So what is next? Further, it was some kind of "mysticism". Further, it was the beginning of the "big life circle", the beginning and the end of which was "Smoke Bay" (I remind you, Reykjavik), which because of the pillars of steam rising from hot springs, made a big impression on the first settlers of Iceland-the Norwegians and Celts.

In 1960, in Reykjavik, Robert Fisher became the first-ever winner in an international tournament for the first time, scoring 3 wins in 4 games with one draw. In the following year, 1961, the "formation" of the young "prodigy" as one of the first-rate chess stars continued: a "draw match" with S. Reshevsky (2 wins, 2 losses and 7 draws) and 2nd place on the A. Alekhin memorial, but (!) without a single defeat with 8 wins and 11 draws. At the beginning of 1962, R. Fisher distinguished himself by a brilliant victory at the interzonal tournament in Stockholm, where he scored 17.5 out of 22 points (13 wins, 9 draws and, again (!), not a single defeat) and won 1st place. According to the words of Anatoly Karpov, 12th world champion, much later, "the young American finished with a huge margin, literally humiliated all his rivals ..."

Next, take the text from Wikipedia: "In 1962, at the next tournament of applicants in Curaçao, he again suffered a failure - the 4th place, after Petrosian, Keres and Geller. After returning home, Fisher published an article in the magazine Sports Illustrated, in which he declared that the strongest Soviet chess players play contractual draws between themselves so as not to let other contenders be the first place (in this tournament all 12 games between Petrosian, Keres and Geller ended in a draw, bringing each of the favorites an equal number of points). According to Fisher, 'Russian control in chess has reached a level where fair competition for the title of world champion is no longer possible.' Speaking objectively, holding the highest positions with the help of contractual draws was possible, but only because Fisher really did not keep up with the favorites. If he really claimed the first place, the Soviet grandmasters could stop it only by winning from each other. And Fisher himself in one of the games with Geller agreed to a draw on move 14, and with Keres - on move 12. Fischer said that he refused to participate in competitions for the highest title until FIDE replaces the candidates' tournament with matches according to the Olympic system, knockout, and indeed did not participate in the candidates' tournaments for several cycles. Subsequently, self-critical approaching the assessment of his chess creativity, he still made the right conclusions from his failures."

The next three years were spent by R. Fisher mainly in "home", i.e. in the USA, the matches in which he invariably was the first:

1962-1963: XVII US Championship (6 wins, 1 loss, 4 draws); 
1963: Western States Open Championship (7 wins, (!) not a single defeat, 1 draw) and the New York Open Championship (7 out of 7 (!) Points);

1963-1964: XVIII US Championship (again (!) 11 out of 11 points).

In 1965, Robert Fisher took part in the IV memorial of the outstanding Cuban chess player Capablanca, held in Havanna, dividing 2-4 places (12 wins, 3 losses, 6 draws). But he participated in it in absentia, transferring his moves from the USA to Havana by phone and teletype. This was because in the 1960s, the United States imposed sanctions on Cuba, and the US State Department did not allow Fisher to leave for Havana.

Interestingly, if we follow the hypothesis of V. M. Glushkov, did not R. Fisher's contact with the CIA (Central Intelligence Agency) of the USA start from this "absentee" tournament? Moreover, the "special services" of the USA, the FBI (Federal Bureau of Investigation), first of all, "looked after" Robert's mother of Regina, who did not hide her left-wing views as a possible "Soviet spy" until her death in 1997. And Robert himself, after visiting Moscow in 1958, and even for a good knowledge of Russian, was a long time on suspicion of the "special services" of the United States.

If in the three international tournaments that followed Havana (in Los Angeles, Monaco and Skopje), Robert Fisher still suffered 6 losses (3, 1 and 2 , respectively) with 25 wins and 13 draws, then in 12 tournaments of the next 4 years (1968-1971) he suffered only 5 defeats with 108 wins (!) and 40 draws. And this, including the under-played interzonal tournament in Sousse (10 games without a single defeat), the international blitz tournament (1 loss with 17 victories and 4 draws) - 1 st place, the XIX Chess Olympiad (1 loss, the one mentioned earlier, from Boris Spassky), matches with contenders for the "chess crown" M. Taymanov, B. Larsen and T. Petrosyan (1 defeat).

Note that in the above-mentioned international blitz tournament, held in 1970 in Herceg Novi, Yugoslavia, it is highly doubtful that R. Fischer was able to take 1st place using the "tips" of a computer chess program. It is possible that his rational style of play, "life in chess" and the development of debuts and endgames he had carried out, he was already provided with an undoubted advantage (in the blitz games) in this tournament.

(In support of these words (a blacksmith forges a horse and a toad puts a foot in), the author would like to give the story with a "chess" episode from his own life during the author's stay at the head of the Section of Automated control systems of technological complexes (ACSTC) in the Special Design Bureau of Mathematical Machines and Systems (SDB MMS) of the Institute of Cybernetics. The author, taking up "on the orders of" non-standard position of the head of the Section, staffing was the chief of the Department of mathematical and algorithmic support of ACSTC. The chiefs of the other units in the Section of ACSTC were Leonid Tkachenko (the Department of information and software support of ACSTC), Paul Sakhno (the Department of technical support of ACSTC) and Henry Massalsky (the Laboratory of automated control systems in chemical engineering).

According to the Program of Works concluded between, on the one hand, the Academy of Sciences (AS) of the Ukrainian SSR "represented" by the Institute of Cybernetics (IC) and, on the other hand, the USSR Ministry of Petroleum Industry (MPI) "represented" by the General Directorate of Oil Transportation (GDOT), the Section of ACSTC was necessary to create in 19785 Automated control systems of technological processes (ACSTP) on the main oil pipelines (MOPL) in the Dispatcher stations located in such settlements as Almetyevsk (Tatarstan of the Russian Federation, Office of the North-West MOPL in Bugulma), Nurlino, $100 \mathrm{~km}$ from Ufa (Bashkiria of the Russian Federation, Office of the Ural-Siberian MOPL in Ufa); Yaroslavl (Russian Federation, Office of Upper Volga MOPL in Gorky, 
now Nizhny Novgorod), Michurinsk and Kuibyshev, now Samara, of the Russian Federation (Office of the "Druzhba" MOPL in Lviv, Ukraine).

To collect data on the objects in order to develop the Technical Tasks (TT) for the creation of the specified ACSTP, in the first decade of January 1978, the department heads of D. Karachenets, P. Sakhno and L. Tkachenko set off. The route of the written out business trips included Moscow, Gorky, Bugulma, Almetyevsk, Ufa, Nurlino, Kuibyshev and Michurinsk.

But I allow myself a small digression from the “episode". P. Sakhno, who left, unfortunately, 5 years and 9 months out of life after the episode described from an asthma attack, was a passionate chess player. Coming on Mondays before everyone else in the Section of ACSTC to work, he often shared his impressions of "a successful Sunday," when "in nature, in the forest" he could play plenty of blitz with one of his rivals, playing, for example, 60 games and 40 from them winning. The Reader should not assume that the departure "to nature" was accompanied by the reception of "strong drinks". Not. Paul Sakhno was "an absolute teetotaler".

Returning to the "episode", I would note that already at the very beginning of the journey, Paul Sakhno and the author had a lot of free time so that he could persuade the author "to play a couple of chess games". The first such games took place in the carriage of the Kiev-Moscow fast train, where the "chiefs" were only three in a compartment and the players did not cause inconvenience to their colleague L. Tkachenko, who, on the contrary, observed as P. Sakhno "routed", literally, "the main chief" of D. Karachenets: in ten blitz games played Paul Sakhno easily scored 10 victories over "his rival". I note that $P$. Sakhno, as it turned out, took the chess clock on the road with him.

Upon arrival in Moscow, where the "chiefs" were supposed to linger for three days, in the evening of the first day while waiting for several hours for an unreserved room at the hotel, the "rivals" sat down again in the hotel lobby behind the chessboard. Only now the author, not very tempted in chess debuts and not having a long time ago, by the time of match practice, suggested Paul Sakhno to play the "standard" games. But only one game was played, "saturated" with a positional game with many pieces. The party took a lot of time and ended with the victory of the author of the story (The Reader should not suspect that it was not the "equal rival" that won, but the "main chief").

In the evening of the second day of their stay in Moscow, having decided the necessary questions at GDOT, the "heads" visited the Stanislavsky and Nemirovich-Danchenko Theater, and in the evening of the third day they again went by train compartment to Gorky. The train left at 7 o'clock in the evening and therefore the next game of "rivals" still could not prevent the fourth, outside passenger of the compartment. In the second "standard" game, Paul Sakhno won. The author may have been affected by "fatigue", since in dealing with issues in Moscow, from him as the "main chief" more "power efficiency" was required.

In the Office of Territorial Upper Volga MOPL in the city of Gorky, the head of the Department of instrumentation, automatics and telemechanics of this Office was N. Mishin. He at a meeting with the head of the Office V. Sedov raised the question of that the Yaroslavl Region MOPL, included in their Territorial Upper Volga MOPL and on which one of the five ACSTPs of 1978 was to be introduced, became the "base" object for the introduction of the new version of the Base ACSTP created in the Rovno Region of the "Druzhba" ("Friendship") MOPL and successfully passed the State tests at the end of 1977. I would note that the prerequisites for this proposal of N. Mishin were because the specified ACSTP were created on new CCC (Control Computing Complexes), M-7000 with a very advanced DOS RT (Disk Operating System of Real Time), developed in the Ukrainian 
Severodonetsk Scientific Research Institute of CCM (Control Computing Machines), and new telemechanical complexes TM-120, developed at the Ministry of Instrument Engineering and Communications of the USSR (Moscow).

Coordination of this question, "on the one hand," N. Mishin together with the author of the narration, and "on the other hand", with the technical management of GDOT in Moscow on departmental communication, the "oil communication", demanded a lot of effort from the "main chief". I note that for the author, as well as his "chiefs", colleagues who accompanied him, such a turn of events presented itself worthy of consideration given the interests of the staff team of the ACSTC Section. Therefore, the "rival" "weakened" and less tempted in debuts again, but in the evening in a departmental hotel, was defeated, and the score was 2:1 in favor of P. Sakhno.

On the second day, the question of assigning the status of a "base" object to Yaroslavl Region MOPL was finally resolved and the "chiefs" had time to study the "base" object for technical documentation that was in the "superior" organization in relation to the Yaroslavl Region MOPL - the Territorial Upper Volga MOPL. This work did not require much effort. And in the evening, the author of the narrative still had enough strength to withstand a stronger "rival" and, moreover, to win. The score became 2:2.

The next day, the "chiefs" were to take place on the official transport of the Upper Volga MOPL in the city of Bugulma, to the Office of the Territorial North-West MOPL. However, the night before, in the city of Gorky and in the surrounding regions of the Russian Federation, there was a snowfall that completely paralyzed road, rail (!) and air traffic between the city of Gorky and further points of the "chiefs" mission (Almetyevsk, Bugulma, Kuibyshev, Michurinsky, Ufa with Nurlino). How can you not say "Russia is not Ukraine" by analogy with the title of the book by ex-President of Ukraine Leonid Kuchma "Ukraine is not Russia". Only the return journey to
Moscow remained available.

When we reached the Office of Territorial Upper Volga MOPL on foot, we agreed with the technical management of GDOT our return to Moscow to discuss the future course of the Program of works in 1978. Good was received ("a blessing in disguise") and the Office at the railway station reserved compartment for an evening train to Moscow. Having decided on some more things, we returned to the hotel after lunch, complemented by a cup of coffee. Here, having taken a shower, the author of the narration still "above" raised his "fighting spirit" and in the next, last "standard" game, extremely dynamic and, at the same time, saturated with figures, he could win a decisive victory over his more experienced "opponent".

On the way back to Moscow, and then, on the same day after arriving in Moscow-to Kiev, we played, but only in a blitz, about 30 games that Paul Sakhno won to everything. He was the pattern of the "rational chess machine"!

This episode is given in the narrative in order to show how in a chess game the victory of one of the rivals over the other depends on many factors. Of course, the game of "chess gods on Olympus" in its quality is several times higher than the game of "simple chess mortals". But, I think, the problems of the debut preparation and the "fitness form" are also important for them ...).

The author apologizes to the Reader for such a vast departure from the main topic. After all, "for someone that hurts, that is what he is talking about."

Returning to the achievements of Robert Fisher, we note that at the World Chess Olympiads, in which Fischer led the US team, he played 65 games against the world's leading chess players, winning 40 games, losing only 7 games and 18 bringing in a draw.

And now, dear Reader, let the story's author make a "turn to $180^{\circ}$ " to refute the "main hypothesis" of Academician V. Glushkov that Robert Fisher used "hints" of the "Computer chess program" in the last 
four matches during the "takeoff" of the chess Olympus. And in return to offer another "one hypothesis", but with a "turn of only $90^{\circ}$ ".

\section{Results and Discussion}

\subsection{A Brief History of Computer Chess Programs}

To this end, we will briefly review the history of computer chess programs. "Briefly" because it is almost impossible to "survey" all that "computer scientists" have developed, and, especially, programmers in this field over the past 65 years or so.

But as for the more "deep" history, it is easier here. But we refer only to some historical facts, which the Reader will find in special literature or, more easily, on the Internet. The first "chess machines", created in 1769 ("Mechanical Turk") and almost a hundred years later in 1868, were pure fraud: a human player was hidden in them. And now the "chess machine" that the Spaniard Leonardo Torres Kvevedo built in 1912 was closer to the "theme": the machine could "play" the "King + Rook" endgame against the "King". It is clear how far this automaton was from the desired.

Apparently, "the father of cybernetics" Norbert Wiener was among the first, if not the first, who in his book "Cybernetics", which the author of the narration met in the summer of 1959 after graduating from the Kiev Polytechnic Institute, offered how to create a chess program, using minimax search with limited depth and evaluation function. The book of N. Wiener was published in 1948, and already in 1950 Claude Shannon published one of the first articles on the topic "Programming a computer for playing chess" and in 1951 Alan Turing developed on paper the first chess program, although the algorithm of such a program he defined as early as 1947.

Claude Shannon paid special attention to the problem of the "curse of multi-variant" problem when the chess program will be trying to find the best every next move in the game. His name is associated with the number of Shannon- $10^{120}$, with which mathematicians estimate the number of possible chess games, one of which could be played in one game.

(It should be noted that the number of atoms in the studied part of the universe of astrophysics is estimated by "only" the number $10^{80}$ ). True, the number of possible admissible positions that can arise on a chessboard is "substantially" less - only " 1040 " (this is multiplied by a billion times a billion and another two times a billion and another ten thousand!). Shannon noted that theoretically the best move in each position exists, but it is almost impossible to find it in the initial steps of a chess game.

Shannon singled out two ways of sorting out the variants when "playing" a computer program of a chess game. In the first method (A-strategy), the chess program enumerates all variants without exception (the brute force approach), studying each possible position to a fixed depth using the Minimax algorithm. Shannon saw two shortcomings in this method: (1) to view positions only three moves ahead on both sides of the computer, in order to meet the "standard" time allowed for the game, it would be necessary to estimate up to 1 million positions per second (such computations the technology was able to reach only 40 years later, whereas the speed of the first computers created at the time of writing the article by Shannon was calculated only by the thousands of arithmetic and logical operations per second); (2) with the A-strategy, chess programs could make gross mistakes, trying to estimate the position at the beginning of the exchange of figures or other important sequence of moves, such as, for example, at the beginning of a tactical combination (this is the so-called static state problem).

Overcoming these shortcomings, Shannon saw in the use of the B-strategy when the chess program discards inappropriate options, based on the experience of the leading chess players.

The Minimax method requires viewing a large number of options. Significant, by an order of magnitude, their reduction can be achieved through the use of the alpha-beta clipping algorithm in 
computer programs found by scientists at the University of Pittsburgh in the USA in 1958. This algorithm seems to the author to be somewhat similar to the method of sequential analysis of options in optimization theory.

And although this algorithm and its variations allow for some time to "look ahead" (deeply) to a chess game for a larger number of moves, however, it also does not give an opportunity to get rid of the "curse of multivariance". And when viewing in advance of a chain of moves stops, how should the chess position at the end of such a chain be evaluated? In modern chess programs such an assessment is given in conditional pawns and pawn lobes. In pawns, the "material" of the chess position for each of the opposing sides is first evaluated: a pawn, like a pawn-1; knight and bishop-3 (pawns); rook-5; the queen-9; the king is $\mathrm{K}$ (pawns), where $\mathrm{K}$ is a deliberately large number. Then, in pawn fractions (tenths and hundredths), various, very numerous factors associated with the position are evaluated. And such an assessment may require quite a lot of computational work and lead to noticeable computer time (or a whole computer system) loss on each checked course, which, for example, with "standard" playing time (40 moves in 2 hours of play) limits the "depth" of view.

And here, by the beginning of the 70 s of the last century, "chess" programmers developed a number of methods. Let us cite at least the "deepening" method, in which the program tries to evaluate some positions "deeper", going beyond the established "horizon of visibility" (for example, when exchanging pieces or playing a combination).

And, nevertheless, if you look at the history of chess programs today, you can see that at the beginning of the 70s, when Fischer's "take-offs" on chess Olympus took place, these programs could not compete with ordinary chess masters, but especially, grandmasters, contenders for the chess crown, and world champion.

In confirmation of the above, the author refers to an excerpt from the section "Computer against Man" in the article "Computer Chess", taken from Wikipedia:

"Even in the 1970s and 80s, the question remained open as to when the chess program would be able to defeat the strongest chess players. In 1968, international grandmaster David Levy went on betting that no computer could beat him over the next ten years. He won the bet by defeating Chess 4.7 (the strongest at the time) in 1978, but he was aware that there was not much time left before computers won world champions. In 1989, the Deep Thought program won against Levi."

Note that it was in the first time frame, say, the 11-year-old interval of 1968-1978, that Robert Fisher "took off" to the chess Olympus. And, as we see, even the strongest chess program at the end of this interval could not yet stand against the "ordinary" international grandmaster. And only after next 11 years, the chess program was able to beat this grandmaster.

In order to understand how the chess programs have progressed during this second interval, let us turn to the article by G. Lukashenko "Algorithms of Chess Programs", with which the reader can get acquainted on the Internet. In "Part IV. Improvements" the author of the article, speaks about improving the quality of chess programs in those years, notes:

"Partially, progress is explained by the rapid development of hardware - personal computers in some settings reached the level of supercomputers of the late 70s (although in a number of parameters they are still seriously lagging behind). The development of algorithms is partially 'guilty'-there was no breakthrough, but there were a lot of evolutionary improvements. What are the main ones?"

Let us list these improvements: (1) use of debut library; (2) use of databases with fully calculated endgames; (3) thinking during the opponent's turn; (4) various heuristics that help sort the moves in the brute force process; (5) iterative deepening; (6) hash tables; 
(7) idle; (8) the only answer. For the Reader to understand the essence of these improvements, we refer him to the original source.

Here we will continue the excerpt from the section "Computer against Man":

"But the programs were still well below the level of world champion, which Garry Kasparov demonstrated by defeating the same Deep Thought twice in 1991.

It lasted until 1996, when Kasparov held a match with IBM's Deep Blue computer, where the champion lost his first game. For the first time, a computer chess program beat the world champion with standard time control. However, Kasparov changed his style of play, winning three and drawing two of the remaining five games. In May 1997, an enhanced version of Deep Blue defeated Kasparov with a score of 3.5-2.5."

As we see, 25 years have passed since Robert Fisher won the World Chess Championship title before "Computer" could win the match of 6 games against the World Champion with a slight margin. And what is "Computer"? Here is an excerpt from "Part VII. How is the Deep Blue built?" of the mentioned article of Lukashenko:

"Deep Blue II is based on IBM's powerful RS/6000 server. The server has 31 conventional processors; one declared the main, obey 30 others. 16 specialized chess processors are connected to each 'working' processor, so there are 480 chess processors in total. They are the 'heart' of the system, thus the statement of IBM 'We are selling an RS/6000 server that beat Kasparov to chess', how to say it: not quite right."

The author of the present narration will not go deeper into the history of computer chess, believing that what has been said is enough to, to put it mildly, refute the intriguing hypothesis, told V. Glushkov his "bewitched" the audience in the room "suite" of "Verkhovyna" hotel in Lviv dark night of August 8, 1979.

But, on the other hand, "fact on the face": Robert Fisher in 1971-1972 scored incomprehensible victories over his rivals, who were at that time at the very top of the "chess Olympus". Why?

\subsection{Robert Fisher and Cold War}

To answer this question, we first give an excerpt from the section "Characteristics of Creative Manners" of the Wikipedia article, the data from which were taken above at the beginning of the answer to the question "So who was Robert Fisher?":

"He was distinguished by extraordinary performance, fanatical devotion to chess, and encyclopedic knowledge. Fisher was an outstanding debut researcher and enriched chess theory with a variety of developments. The absolute majority of his games Fisher began with the royal pawn 1.e4, brilliantly playing both open beginnings (including the royal gambit) and half-closed ones. Known so-called. 'Fisher's defense' in the royal gambit (1.e4 e5 $2 . f 4$ ef 3.Kf3 d6). Fisher's successes in the swap version of the Spanish party made fashionable this branching of the popular debut for a long time. With black Fisher fought for the initiative, usually playing in response to the 1.e4 Sicilian defense (most often the Najdorf variant), and on 1.d4 the Old Indian defense and the Grunfeld defense. In the match with Spassky (1972), Fisher appeared transformed - his debut arsenal was enriched with new thoroughly developed principles.

Fisher managed to follow not only the competition among men, he also studied parties from women's tournaments ..."

In order to understand where Fisher's "debut arsenal was enriched with new thoroughly developed principles" when "taking off" to "chess Olympus" (and not only in the match with Spassky), the author, first, "looked through" on the chessboard all the games played Robert Fisher against his opponents in the four cycle of games described; secondly, tried to study in more depth the biographical data from the life of Fisher for several years preceding these matches and, thirdly, to get acquainted with the memoirs of the "Gods of Chess Olympus," whose memories concerned that period. The main source of data for the 
author was Sergiy Voronkov and Dmitry Plisetsky's book 'Russians vs. Fisher', published in 2004 in Moscow by the publishing house RIPOL CLASSIC in the series "The Art of Chess" (since 2001) under the general editorship of international grandmaster Yuri Averbakh.

In their preface "To the Readers," the authors "lift the veil" over the "Fisher problem" in the USSR:

"At that time almost the entire elite of Soviet chess took part in a detailed study of Fisher's personality: Petrosyan, Spassky, Tal, Botvinnik, Smyslov, Keres, Taimanov, Korchnoi, Geller, Averbakh, Bondarevsky, Boleslavsky, Polugaevsky, Kotov, Krogius, Vasyukov, Balashov, Shamkovich ... And not so long ago, secret documents of the Central Committee of the CPSU emerged from non-existence, from which it became clear what role the political grandmasters from Old Square played in the fight for the world chess crown.

Of course, the theme 'Russians vs. Fisher' is much broader, because it includes not only the history of relations between Soviet chess players and Fisher, which is densely mixed with politics, but also the richest chess material-more than 150 of his games with the leaders of the Soviet chess school ..." (more precisely, 158 games, author).

And, as a continuation of the "history", it is an excerpt from the preface "Instead of the Preface" by the editor of the book Y. Averbakh:

"In the context of the cold war between East and West, Soviet ideology sought to turn chess fights with Fisher into political fights, into a struggle between two worlds, two systems."

But, as the "history" shows, and the leader of the West - the USA also did not shy away from this struggle. As an example, to begin with, let us give an episode that took place at the inter-zonal tournament in Sousse (Tunisia), held in October-November 1967.

For this tournament, Robert Fisher appeared as a zealous believer, a supporter of the Baptist sect of Seventh Day Adventists. The second representative of the USA, International Grand Master Samuel
Reshevsky, a veteran of chess in the USA, turned out to be a zealous believer, only a supporter of Judaism. Both from Friday to 19 o'clock on Saturday could not play for religious reasons. and also, on religious holidays. Under them the time of all games in the tournament was determined, which caused considerable inconvenience to all other participants of the tournament. And when this led to the fact that Fisher had four days to play four games in a row, he ultimately demanded one additional day off, threatening to leave the tournament. Knowing the character of "Bobby," another representative of the United States at the tournament, Grandmaster Byrne, reported Fisher's intention to the US Embassy in Tunisia. The secretary of the embassy, a woman, arrived in Sousse from the city of Tunisia, but she arrived unsuccessfully: on the "day of prayers" of Fisher. Waiting for the end of the "religious ban", she told Fisher that he represented the United States at the tournament. To which Fisher, stating that he represents only himself, packed his bags and went to the city of Tunisia. Having missed two games, between which he still managed to defeat his compatriot Reshevsky, and having received two "defeats", he finally realized that the organizers of the tournament decisively refused to meet his demands. When, once again in the city of Tunis $(140 \mathrm{~km}$ from Sousse), he "surrendered" and declared his readiness to continue participating in the tournament, so that Fisher would have time to come to the next meeting with Bent Larsen, the American embassy gave him the fastest car. A helicopter was sent to the highway, which was supposed to patrol the highway and provide a "green street" to the car with Fisher. But, time was lost, Fisher was credited with the third "absenteeism" and excluded from further participation in the tournament. Robert Fisher, gaining 8.5 points in 10 games, missed his chance to become the winner of this tournament. The winner was Bent Larsen, who collected 15.5 points in 21 meetings ("Expensively", then the Danish intransigence on the matter of 
postponing his party with an American for an hour cost him).

Even greater interest from the US government structures was shown to R. Fisher's games during his "ascent" to the chess Olympus, and, especially, during the Spassky-Fisher match. And why? Because the leader of the Republicans in the USA, Richard Nixon, who became the President of the United States in 1968, was preparing for a new election campaign and the second term of his presidency. Nixon's "piggy bank" already had a number of achievements (the landing of American astronauts on the moon, the second, after F. D. Roosevelt, the trip of the American president to the USSR, the first trip to Beijing, a series of steps to stop American participation in the war in Vietnam) Fisher's victory over Spassky in the decisive "battle for the chess crown" also had "weight".

Therefore, it seems to the author that "in the context of the cold war between East and West" and the "American ideology" also looked at Fisher's chess matches with the "Russians" as "political battles", "the struggle of two worlds, two systems".

\subsection{Robert Fisher and a Computer Chess Program}

And if now the author makes an assumption that between the interzonal tournament in Sousse dramatically ended for Robert Fisher in the fall of 1967 and his new "phenomenon" to the chess world in the spring of 1970 in the "match of the century" of the USSR national team in four a circle on 10 boards, where Fisher, who played on the second board (giving up the first Bent Larsen), defeated Tigran Petrosyan twice and managed to make draws twice in stubborn fights, Fisher did not "sit with folded arms", but strenuously trained using the access granted to himto the "computer chess program", this may not surprise the Reader. The author will try to strengthen this assumption with the following arguments.

In the above-mentioned book Russians against Fisher there is one interesting recollection of the
Yugoslav chess player D. Belitsa, one of the few journalists with whom Fisher was ready to communicate. Somewhere at the end of the "match of the century," Belitsa asked Fisher to give an interview to the readers of the weekly 64, whose editor-in-chief was Petrosyan. After this, R. Fisher talked with T. Petrosyan, during which Fischer ..., for example, asked Tigran whether he played checkers. He also said that he believes in chess computers that will win even world champions. When it will be? It all depends on how many scientists will work with the machines. The emphasis in this passage from D. Belitsa's memoirs is made by the author of the present narration, who would like to ask the Reader: "And where does Fisher come from? Not from his own religious beliefs." This is the first argument in defense of the hypothesis put forward.

And the continuation of the above passage from the memories of Belitsa:

"When Petrosyan left, I asked Fisher if he expected victory over him.

-When I was going to fly here from America, I thought that it would be harder for me to play with Petrosyan than with Spassky. Here, however, it turned out that neither Petrosyan nor I was in better state.

- So you are unhappy with your game?

-Yes, I am tired of the road. It was also hampered by the one and a half year absence of serious practice. It is especially important for me to play now, and I would really like to play in an interzonal tournament. Of course, it will be difficult to get there because I did not play in the US Championship ..."

And again the underscores in the words of Fisher are made by the author. Something strong was supposed to captivate Fisher so that he would not seriously play for a year and a half, and not even participate in the next US Chess Championship. And this "something", according to the author, was most likely a fascination with "computer chess program", with the help of which he was able to turn out debuts and endgames in games. And this is the second 
argument in defense of the hypothesis put forward.

And now, Reader, let us turn again to the history of computer chess set forth in Wikipedia. Here is an excerpt from it:

- "1956, John McCarthy invented the alpha-beta search algorithm.

- 1958, NSS was the first program to use the alpha-beta search algorithm.

- 1958, the first chess programs that could be played by full chess games were one created by Alex Bernstein and the second by Russian programmers.

- 1962, Kotok-McCarthy was the first program to play plausibly.

- 1966-1967, the first match between programs.

- 1967, Mac Hack Six, developed by Richard Greenblatt, was the first program to win a man in tournament time control.

- 1970, the first year of the North American Computer Chess Championship.

- 1974, Kaissa (USSR) won the first World Computer Chess Championship."

The year of the "match of the century" coincided with the first year of the North American Computer Chess Championship. And then the question arises:
"Maybe Robert Fisher not only honed his skills with the help of a computer chess program, but also himself participated in the development of such a program?"

In any case, the author considers the given information as the third argument in defense of the hypothesis put forward.

\section{Conclusions}

Maybe after the publication of this article, it will fall into the hands of someone in the United States and someone will be found who will confirm or refute this hypothesis.

As for the author, he certainly does not exclude the option that the subsequent victories of Fisher were the result of his independent preparation.

\section{References}

[1] Wikipedia. Mark Taimanov.

[2] Wikipedia. Bent Larsen.

[3] Wikipedia. Tigran Petrosian.

[4] Wikipedia. Boris Spassky.

[5] Wikipedia. Bobby Fischer.

[6] Wikipedia. Norbert Wiener.

[7] Wikipedia. Claude Shannon.

[8] Wikipedia. Computer chess. 